\title{
Prevalence of Parkinson's disease in an urban area of Cienfuegos city
}

\begin{abstract}
Background: Numerous populations' studies have reported that Parkinson's disease is more common in highly industrialized countries than the agricultural societies and more frequent in Europe and North America than the Far East. Studies carried out in urban areas of Cuba report a prevalence of $135 / \neg 100000$ inhabitants.

Objective: To determine the prevalence of Parkinson's disease in an urban area of Cienfuegos.

Method: A descriptive-prospective study was conducted. The study included all the patients diagnosed with Parkinson's disease belonging to the Area II in the Cienfuegos' municipality; a total of 31 patients were included in a region where 8681 patients are 60 years old or even older.

Results: For a total of 42028 patients, 8681 were 60 years old or older, and 31 suffer from Parkinson's disease $(27=65$ years $)$, with a prevalence of the masculine sex $(15 / 12)$ and an average of age of $77.6 \pm 8.6$. The index of prevalence (IP) of patients older than 60 years was $357.1 / 100000$ inhabitants and the totality of the population reached 73.8/100000 inhabitants being the average of IP for patients older than 60 years, in other latitudes it fluctuates in 147.7/100000 inhabitants.
\end{abstract}

Conclusions: This study demonstrates the high index of prevalence for people older than 60 years, which keeps above the average worldwide.

Keywords: Parkinson's disease; Prevalence; demographic features

\author{
Volume 3 Issue I - 2019
}

\author{
Julio López Argüelles,' Luis A Borroto \\ Bermudez, ${ }^{2}$ Leydi María Sosa Aguila, ${ }^{3}$ Aleima \\ Rodríguez Carbajal ${ }^{4}$ \\ 'Department of Neurology, University hospital Gustavo \\ Aldereguía Lima, Cienfuegos, Cuba \\ ${ }^{2}$ Student aide in Neurology, Medical University "Dr. Raúl \\ Dorticoz Torrado", Cienfuegos, Cuba \\ ${ }^{3}$ Department of Genetic, University hospital Paquito Gonzalez \\ Cueto, Cienfuegos, Cuba \\ ${ }^{4}$ Department of Neuropsicology, University hospital Gustavo \\ Aldereguía Lima, Cienfuegos, Cuba
}

Correspondence: Julio López Argüelles, Department of Neurology, University hospital Gustavo Aldereguía Lima, Cienfuegos, Cuba, Email juliola@jagua.cfg.sld.cu, julito, arguelles@gmail.com

Received: December 10, 2018 | Published: January 24, 2019

\section{Introduction}

Parkinson's disease (EP), described for the first time in 1817 by James Parkinson in its monograph of 66 pages An Essay on the shaking palsy, where points it out as a condition consisting of shaking involuntary movements, with reduction of the muscular potency in the passive and active mobility, with propensity for encorvar the trunk before, remains as the second degenerative disorder of the central nervous system after the Disease of Alzaheimer. ${ }^{1,2}$ Within its etiology or risk factors deserves special interest the age, then this is directly proportional to degenerative processes, the mean age of beginning is of 60 years, and the incidence increases significantly with the age. ${ }^{3}$ However, around the 5 to 10 percent of the people with Parkinson's disease has a disease of "early beginning" that begins before the 50 years old. Other investigators believe that the disease is result of a combination of genetic susceptibility and exposure to one or more environmental factors that trigger the disease. ${ }^{4}$ Numerous population studies have documented that Parkinson's disease is more common in the very industrialized countries that in the agricultural societies, and most frequent in Europe and North America that in the Far East. ${ }^{5-8}$ The analysis joint of 5 European Communities did not identify any substantial difference in the prevalence of the EP in the European countries and the general prevalence was 1.6 per 100 population. The variable incidence rates in different cultures at least are partly related to the lack of uniform criteria for diagnosis. ${ }^{9}$ In vat studies carried out in urban areas report a prevalence of 135/100000 inhabitants..$^{10}$ In our province are no studies conducted to know the Parkinson's disease patterns, prevalence and incidence which means that intended to start with an area of representative health of our city.

\section{Methods}

We conduct a descriptive study. For the same include all the patients with diagnosis of Parkinson's disease (PD) belonging to Area II of Cienfuegos City. In total 31 patient of a universe of 8681 patients older than 60 years. Was carried out an exhaustive search for patients through the review of the certificates of drugs of levodopa, bromocriptine, and/or parkinsonil, in all the pharmacies of the area, prior consent of the administration of each one of them, carrying out then the verification in the home according to the direction found in the document, where was verified the certainty of the diagnosis of PD. It in addition went to the office of control of the population census where the demographic datum was obtained from the area. For the performance of the statistical analysis were grouped to the patients into different age groups, analyzing the patterns of different demographic and clinical variables for each group. Were compared the values of the means of the clinical and demographic variables according to age groups. For processing of the data the SPSS statistical program was utilized, for the data analyzed there was taken a level of greater significance than 0.05 .

\section{Results}

As a result of the present work verify that for a total population (42028) of people in the area number two of Cienfuegos City (Table 1), a significant part is represented by individuals older than 60 years (8681) what represents approximately $20.7 \%$ of the total. Representing the majority of the patients the older than 65 years of age group with a total of 5957 individuals. Both in the group from 60 to 64 year and in that of 65 years and more, the female sex prevailed, with a number of 1426 and 3267 respectively. Confirming that population is one with trend aging (Figure 1). Serving the variables related to the age $(\geq 60)$ in the patients with PD Parkinson's disease belonging to this area of Cienfuegos City (Table 2) reveal that the disorder occurred with greater predominance in the group of patients older than 65 years $(n=27)$ representing $87.1 \%$ of the total, remaining a light supremacy in 
the male sex (15/12), that it in addition is non-exempt in the group of patients with ages from 60 to 64 years (3/1). The total of patients with the disease in this extension, resulted to be of 31 , obviating 2 cases died, a woman and man, both older than 60 years old. In the Figure 2 see as is distributed the prevalence of the PD in men and women according to different age groups, where see as this increases in the 2 extreme groups and still greater it is in the group of older than 81 years, corresponding the greater value than the male sex. In the Table 3 see as the prevalence of the PD of the health area was of 357.1 per
100000 population, finding its value maximum in the age group above the 65 years and of this the male sex is kept with the greatest number of patients (15/557.6); being the total prevalence of the area of 73.8 per 100000 population. The Figure 3 show as behaves the prevalence of this population in comparison with the found in different countries, being higher than the mean of these $( \pm 166)$, surpassed only by the study conducted in Chinese woman who presented a prevalence of 522 , fluctuating even up to as low values as 16 in Iceland.

Table I Population older than 60 years, Area II of health of Cienfuegos City

\begin{tabular}{lllllll}
\hline Total population of the area & \multicolumn{2}{l}{$\mathbf{6 0}-\mathbf{6 4}$ years } & \multicolumn{2}{l}{ More tan $\mathbf{6 5}$ years } & \multicolumn{2}{l}{ Total } \\
\hline & $\mathbf{n}=\mathbf{2 7 2 4}$ & & $\mathbf{n}=\mathbf{5 9 5 7}$ & & & \\
\hline & $\mathbf{M}$ & $\mathbf{F}$ & $\mathbf{M}$ & $\mathbf{F}$ & $\mathbf{M}$ & $\mathbf{F}$ \\
\hline 42028 & 1298 & 1426 & 2690 & 3267 & 3988 & 4693 \\
Total $\geq 60$ years & 8681 & & & & & \\
\hline
\end{tabular}

M F

Figure I Distribution of the population pyramid.

Table 2 Patients with Parkinson's disease in Area II of health of the Cienfuegos City

\begin{tabular}{llllll}
\hline $\mathbf{6 0}-\mathbf{6 4}$ años & $\mathbf{6 5}$ años y más & Total & \\
\hline $\mathbf{n = 4}$ & & $\mathbf{n}=\mathbf{2 7}$ & & $\mathbf{n = 3 1}$ & \\
\hline $\mathbf{M}$ & $\mathbf{F}$ & $\mathbf{M}$ & $\mathbf{F}$ & $\mathbf{M}$ & $\mathbf{F}$ \\
\hline 3 & 1 & 15 & 12 & 18 & 13 \\
$12,9 \%$ & & $87,1 \%$ & & $100 \%$ &
\end{tabular}

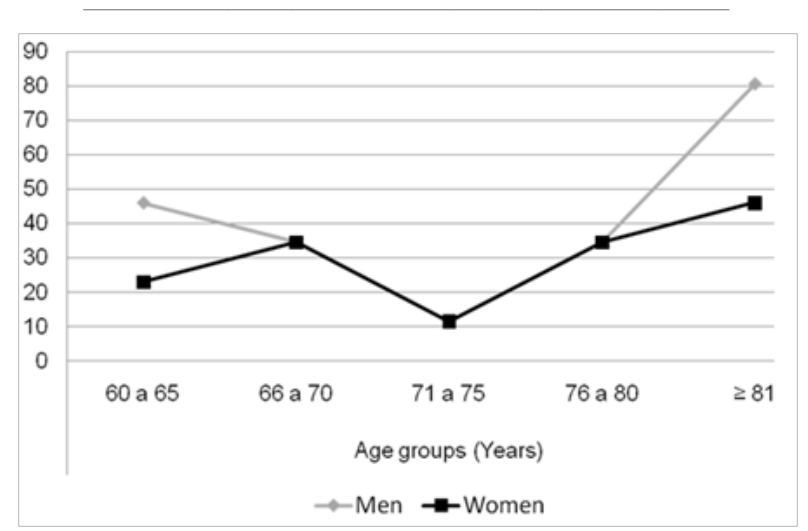

Figure 2 Index of prevalence for men and women according to age groups
Table 3 Patients with Parkinson's disease, cases, and prevalence per 100000 population, by age $\geq 60$ years and sex, in health Area II of Cienfuegos City

\begin{tabular}{llll}
\hline Age (years) & Male & Female & Both sexes \\
\hline 60 - 64 years & & & \\
Population & 1298 & 1426 & 2724 \\
No. of cases & 3 & 1 & 4 \\
Prevalence & 231.1 & 70.1 & 146.8 \\
$\geq$ 65 years & & & \\
Population & 2690 & 3267 & 5957 \\
No. of cases & 15 & 12 & 27 \\
Prevalence & 557.6 & 367.3 & 453.2 \\
Both Age groups & & & \\
Population & 3988 & 4693 & 8681 \\
No. of cases & 18 & 13 & 31 \\
Prevalence & 451.4 & 277 & 357.1 \\
Total population & 42028 & & \\
Prevalence $(\geq 60$ years $)$ & 73.8 & & \\
\hline
\end{tabular}




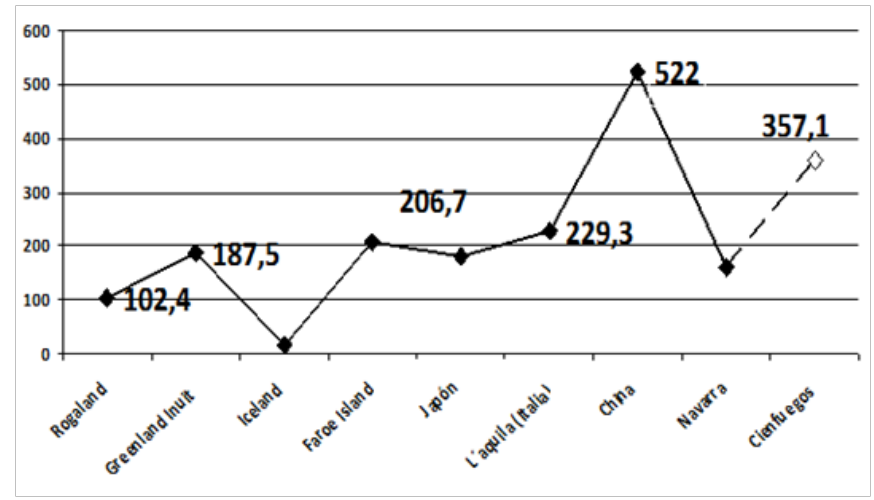

Figure 3 Patterns of the index of prevalence in the population studied with regard to other studies.

\section{Discussion}

The diagnosis of Parkinson's disease is always clinical, which means that the detection of all the affected patients is difficult. The utilized methods for the estimate of the prevalence can be classified in three groups: community studies based on the cases taken care of in the medical consultations; studies door to door, that are capable of detecting up to $40 \%$ of new cases; and the studies of utilization of drugs, ${ }^{11}$ as the one carried out by us, a method which is effective and easy to apply, specifically in a disease as the PD where the Levodopa is the most effective drug and is not utilized in another disease. ${ }^{12}$ The prevalence index (PI) in 357.1/100000 for PD found in our study remains above the mean of the different studies consulted in the bibliography, basically European, ${ }^{13-18}$ becoming evident in addition that are kept men older than 65 years of age as the most affected, as in the majority of the studies although its incidence and prevalence of these is above the 70 years old. ${ }^{19}$ Other works show a PI/100000 inhabitants higher than these figures as in a similar study carried out in China (522) and Sydney (776). ${ }^{20,21}$ The results of the studies of EUROPARKINSON $(1997,2000)$ place the general prevalence of the EP in older 65 years such discharge as 1600 per 100,000 and 1800 per 100,000 , respectively. ${ }^{22,23}$ What is found previously could be with regard to the trend toward aging that presents the population studied shown by the investment of the population pyramid, in addition to being a small population.

\section{Conclusion}

The IP of the area studied is slightly higher than the average of several European studies, behaving the greatest number in men older than 81 years old.

\section{Acknowledgments}

None.

\section{Conflicts of interest}

The author declares there is no conflicts of interest.

\section{References}

1. Parkinson J. An Essay on the Shaking Palsy. Londres, Shrwood, Neely and Jones. 1817. p. 1-14.

2. López-Argúelles J, Sosa-Aguila L, Rodriguez-Carbajal A Blepharospasm followed by Parkinson's disease in two brother's case presentation in a family. Int J Fam Commun Med. 2018;2(4):245-246.
3. Golbe LI. Progressive supranuclear palsy. Semin Neurol. 2014;34(2):151-159.

4. López-Argúelles J, Sosa-Aguila L, Rodriguez-Carbajal A. Deterioro cognitivo en estadios iniciales de la Enfermedad de Parkinson. Rev neuropsicología, neuropsiquiatría y neurociencias. 2014;14(3):77-89.

5. Capriotti T, Terzakis K. Parkinson Disease. Home Healthc Now. 2016;34(6):300-307.

6. Rizek P, Kumar N, Jog MS. An update on the diagnosis and treatment of Parkinson disease. CMAJ. 2016.

7. Shin JY, Habermann B. Medication Adherence in People with Parkinson Disease. J Neurosci Nurs. 2016;48(6):185-194.

8. Vacic V, Ozelius LJ, Clark LN, et al. Genome-wide mapping of IBD segments in an Ashkenazi PD cohort identifies associated haplotypes. Hum Mol Genet. 2014;23(17):4693-4702.

9. Schrag A, Hovris A, Morley D, et al. Young versus older onset Parkinson's disease: impact of disease and psychosocial consequences. Mov Disord. 2003;18:1250-1256.

10. Giroud JL, Collado-Mesa F, Esteban EM. Prevalencia de la enfermedad de Parkinson en un área urbana de la provincia Ciudad de La Habana, Cuba. Estudio puerta a puerta. Neurologia. 2000;15:269-273.

11. Rizek P, Kumar N, Jog MS. An update on the diagnosis and treatment of Parkinson disease. CMAJ. 2016;188(16):1157-1165.

12. Shin JY, Habermann B. Medication Adherence in People With Parkinson Disease. J Neurosci Nurs. 2016;48(4):185-194.

13. Tandberg E, Larsen JP, Nessler EG, et al. The epidemiology of Parkinson's disease in the county of Rogaland, Norway. Mov Disord. 1995;10(5):541-549.

14. Viñes JJ, Labarumbe R, Artázcoz MT. Estudio epidemiológico de la enfermedad de Parkinson en Navarra. ANALES Sis San Navarra. 1999;22:55-66.

15. Totaro R, Marini C, Pistoia F, et al. Prevalence of Parkinson's disease in the L'Aquila district, central Italy. Acta Neurol Scand. 2005;112(1):24 28.

16. Wermuth L, Bech S, Petersen MS, et al. Prevalence and incidence of Parkinson's disease in The Faroe Islands. Acta Neurol Scand. 2008;11(2)8:126-131.

17. Pringsheim T, Jette N, Frolkis A, et al. The prevalence of Parkinson's disease: A systematic review and meta $\square$ analysis. Movement disorders. 2014;29(13):1583-1590.

18. Blin P, Dureau-Pournin C, Foubert-Samier A, et al. Parkinson's disease incidence and prevalence assessment in France using the national healthcare insurance database. European journal of neurology. 2015;22(3):464-471.

19. Claveria LE, Duarte J, Sevillano MD, et al. Prevalence of Parkinson's disease in Cantalejo, Spain: a door-to-door survey. Mov Disord. 2002;17(2):242-249.

20. Rocca WA. Prevalence of Parkinson's disease in China. Lancet Neurol. 2005;4(6):328-329.

21. Chan DK, Cordato D, Karr M, et al. Prevalence of Parkinson's disease in Sydney. Acta Neurol Scand. 2005;111(1):7-11.

22. de Rijk MC, Tzourio C, Breteler MM, et al. Prevalence of parkinsonism and Parkinson's disease in Europe: the EUROPARKINSON Collaborative Study. European Community Concerted Action on the Epidemiology of Parkinson's disease. J Neurol Neurosurg Psychiatry. 1997;62(1):10-15.

23. de Rijk MC, Launer LJ, Berger K et al. Prevalence of Parkinson's disease in Europe: A collaborative study of population-based cohorts. Neurologic Diseases in the Elderly Research Group. Neurology. 2000;54(11 Supple):S21-S23. 